\title{
Chromic Acid Oxidation of Methylaminopyrazole Formamidine in Sulfuric Acid Medium: A Kinetic and Mechanistic Approach
}

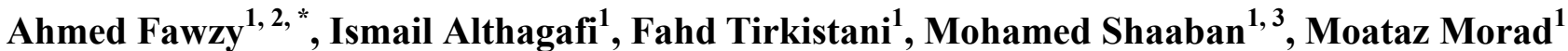 \\ ${ }^{1}$ Chemistry Department, Faculty of Applied Science, Umm Al-Qura University, Makkah, Saudi Arabia \\ ${ }^{2}$ Chemistry Department, Faculty of Science, Assiut University, Assiut, Egypt \\ ${ }^{3}$ Chemistry Department, Faculty of Science, Cairo University, Cairo, Egypt
}

Email address:

afsaad13@yahoo.com (A. Fawzy), iithagafi@uqu.edu.sa (I. Althagafi), drfahd999@gmail.com (F. Tirkistani), rabiemohamed@hotmail.com (M. Shaaban),mhmorad@uqu.edu.sa (M. Morad)

\section{To cite this article:}

Ahmed Fawzy, Ismail Althagafi, Fahd Tirkistani, Mohamed Shaaban, Moataz Morad. Chromic Acid Oxidation of Methylaminopyrazole Formamidine in Sulfuric Acid Medium: A Kinetic and Mechanistic Approach. American Journal of Physical Chemistry.

Vol. 5, No. 1, 2016, pp. 1-9. doi: 10.11648/j.ajpc.20160501.11

\begin{abstract}
The kinetics of chromic acid oxidation of one of aminopyrazole formamidine derivatives, namely $N, N$-dimethyl$N^{\prime}$-(5-methyl-1 $H$-pyrazol-3-yl) formamidine (MAPF)in sulfuric acid solutions has been investigated at constant ionic strength and temperature. The progress of the reaction was followed spectrophotometrically. The reaction showed a first order dependence on [chromic acid] and fractional-first order dependences with respect to [MAPF] and $\left[\mathrm{H}^{+}\right]$. Increasing ionic strength and solvent polarity of the reaction medium had no significant effect on the oxidation rate. Addition of $\mathrm{Ag}^{\mathrm{I}}, \mathrm{Pd}^{\mathrm{II}}$ and $\mathrm{Ru}^{\text {III }}$ catalysts was found to enhance the reaction rate and the order of catalytic efficiency is: $\mathrm{Ag}^{\mathrm{I}}>\mathrm{Ru}^{\mathrm{III}}>\mathrm{Pd}^{\mathrm{II}}$. The final oxidation products of MAPF are identified by spectral and elemental analysis as methylaminopyrazole, dimethylamine and carbon dioxide. A spectral evidence for the formation of chromium(III) product was obtained. A reaction mechanism adequately describing the observed kinetic behavior is proposed, and the reaction constants involved in the different steps of the mechanism have been evaluated. The activation parameters with respect to the rate-determining step of the reaction, along with thermodynamic quantities of the equilibrium constants, are presented and discussed.
\end{abstract}

Keywords: Kinetics, Mechanism, Oxidation, Chromic Acid, Methylaminopyrazole Formamidine

\section{Introduction}

During the few last decades, formamidines have achieved considerable attention because they have a unique and fascinating biological activity including monoamine oxidase inhibitors [1, 2], adrenergic and neuro-chemical receptors [3, 4]. Extensive investigations of $N, N$-dialkyl derivatives of formamidines which are very effective acaricides leads to the discovery of the acaricide-insecticide chlordimeform. Furthermore, the oxidative cleavage of formamidine derivatives is important because it yields $N, N$-dialkyl formamidine group which has various biosynthetic applications.

Formamidines may play an important role in the chemistry of chromium, especially in the environment because of its mutagenic and carcinogenic activity. Chromium in aqueous solutions exists in both trivalent, $\mathrm{Cr}^{\mathrm{III}}$, and hexavalent, $\mathrm{Cr}^{\mathrm{VI}}$, species. However, these two oxidation states are characterized by different physical/chemical behavior and toxicity. The compounds of chromium(VI) pose serious dangers to biological systems, whereas those of chromium(III) are relatively non-toxic [5]. On the other hand, chromium(VI) is one of the most versatile available oxidizing agents for the oxidation of organic compounds. It can be reduced to lower oxidation states by various biological and chemical reductants [6]. The chemistry of the intermediate oxidation states of chromium, $\mathrm{Cr}^{\mathrm{V}}$ and $\mathrm{Cr}^{\mathrm{IV}}$, which observed during the oxidation of organic substrates by chromium(VI) was attracted many researchers because of their implication in the mechanism of chromium-induced cancers [7].

Although, a vast amount of literature is available on the kinetics of chromic acid oxidation of various inorganic [8-11] and organic [12-15] compounds, no reports are available on the oxidation of the biologically active formamidines by this 
oxidant. Therefore, the present work seek to study the kinetics of oxidation of one of the most important formamidine derivative, namely $N, N$-dimethyl- $N$ '-(5-methyl$1 H$-pyrazol-3-yl) formamidine (MAPF) by chromic acid in aqueous sulfuric acid solution. The objectives of such study were to check the selectivity of MAPF towards chromic acid, to establish the optimum conditions affecting oxidation of MAPF, to identify the different chromium intermediate species in such medium as well as MAPF, and finally to elucidate a plausible oxidation reaction mechanism.

\section{Experimental}

\subsection{Materials}

Reagent grade chemicals and doubly distilled water were used throughout the work. A stock solution of MAPF was prepared by dissolving the requisite amounts of the sample in doubly distilled water. Required solution of the chromic acid oxidant was freshly prepared before each experiment and it was standardized spectrophotometrically. Sodium sulfate and acetic acid was employed to vary the ionic strength and dielectric constant in the reaction medium, respectively.

\subsection{Kinetic Measurements}

The reactants were formulated such that the reaction was of pseudo-first order kinetics where the substrate (MAPF) was added in a large excess relative to chromic acid. The reaction was followed by tracing the decay in $\mathrm{Cr}^{\mathrm{VI}}$ absorbance at $\lambda_{\max }=348 \mathrm{~nm}$, its maximum absorption wavelength, whereas the other constituents of the reaction did not absorb significantly at this wavelength. The applicability of Beer's law for $\mathrm{Cr}^{\mathrm{IV}}$ at $348 \mathrm{~nm}$ has been verified giving $\varepsilon=2035 \pm 15 \mathrm{dm}^{3} \mathrm{~mol}^{-1} \mathrm{~cm}^{-1}$. Shimadzu UVVIS-NIR-3600 double-beam spectrophotometer was used for all absorbance measurements.

First order plots of $\ln ($ absorbance) versus time were found to be linear up to more than $80 \%$ of the reaction completion and the pseudo-first order rate constants were evaluated as the gradients of such plots. Average values of at least two independent kinetic runs of the rate constants were taken for the analysis. The kinetic runs were reproducible to within $\pm 4 \%$. A few kinetic runs were performed after bubbling purified nitrogen and compared with those taken under air, and the results were found to be the same. Thus the dissolved oxygen did not affect the oxidation rate. The order of reaction with respect to the reactants were determined from the slopes of the $\log k_{\text {obs }}$ versus $\log$ (concentration) plots by varying the concentrations of substrate and acid, in turn, while keeping other conditions constant.

\section{Results}

\subsection{Stoichiometry}

The stoichiometry was determined spectrophotometrically which indicates consumption of two moles of chromic acid for three mole of MAPF to yield the oxidation products as shown in the following equation,

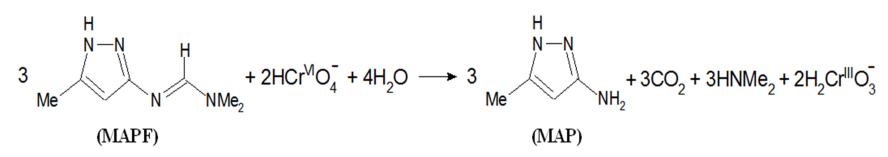

where MAP refers to methylaminopyrazole. The above stoichiometric equation is consistent with the results of product characterization which carried out by spectral and elemental analysis as described elsewhere [16-18].

\subsection{Time-Resolved Spectra}

The spectral changes during the oxidation of MAPF by chromic acid in aqueous sulfuric acid solution are shown in Figures 1 and 2. The scanned spectra shown in Figure 1 indicated gradual decay of $\mathrm{Cr}^{\mathrm{VI}}$ band with time at its absorption maximum, $\lambda=348 \mathrm{~nm}$, as a result of its reduction by the organic substrate (MAPF). Also, there was a simultaneous growing of an absorption band located in the region $395-470 \mathrm{~nm}$ with appearance of two isosbestic points centered at $\lambda=318$ and $393 \mathrm{~nm}$. Careful examination of the spectral scans (Figure 2) manifests simultaneous appearance of new bands located in the wavelength range $390-720 \mathrm{~nm}$. These spectroscopic features are consistent with the formation of a chromium(III) product as reported earlier [19].

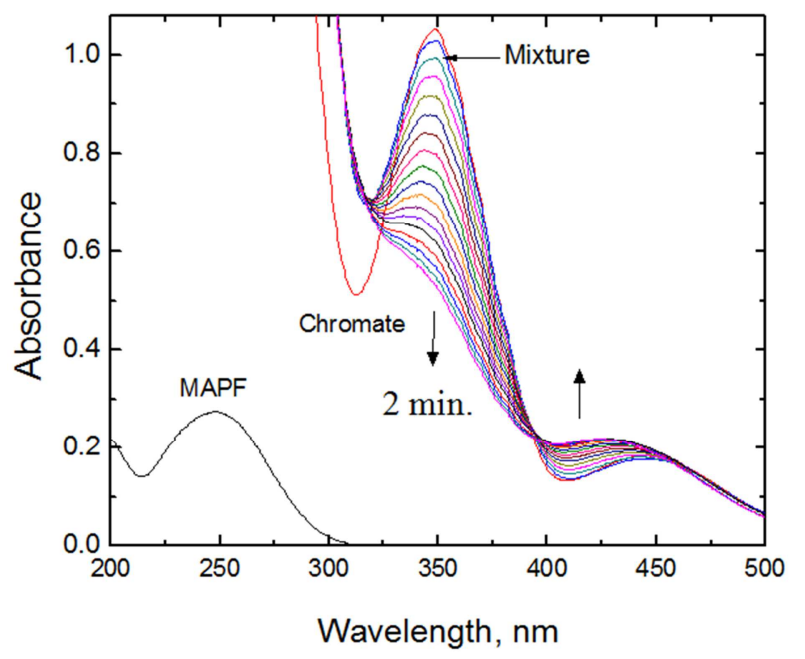

Figure 1. Time-resolved spectra during the chromic acid oxidation of MAPF in sulfuric acid solution. $\left[\mathrm{Cr}^{V I}\right]=5.0 \times 10^{-4},[\mathrm{MAPF}]=0.01,\left[\mathrm{H}^{+}\right]=2.0$ and $I=3.0 \mathrm{~mol} \mathrm{dm}^{-3}$ at $25^{\circ} \mathrm{C}$.

\subsection{Effect of [Chromic Acid] on the Oxidation Rate}

Chromic acid oxidant was varied in the concentration range of $(3.0-8.0) \times 10^{-4} \mathrm{~mol} \mathrm{dm}^{-3}$ at fixed $[\mathrm{MAPF}],\left[\mathrm{H}^{+}\right]$, ionic strength and temperature. Plots of $\ln$ (absorbance) versus time were linear for more than $80 \%$ of the reaction completion. Furthermore, the observed first order rate constant, $k_{\text {obs }}$, was found to be independent of the initial chromic acid concentration as listed in Table 1. These results confirm first order dependence of the reaction with respect to chromic acid concentration. 


\subsection{Effect of [MAPF] on the Oxidation Rate}

The observed rate constant was determined at different initial concentrations of the reductant MAPF keeping other reactants concentrations constant. A plot of $k_{\text {obs }}$ versus [MAPF] was found to be linear with a positive intercept (Figure not shown) indicating that the reaction order with respect to [MAPF] was less than unity. This was also confirmed by the constancy of the second-order rate constants obtained by dividing the $k_{\mathrm{obs}}$ values by [MAPF] at fixed [ $\left.\mathrm{Cr}^{\mathrm{VI}}\right]$.

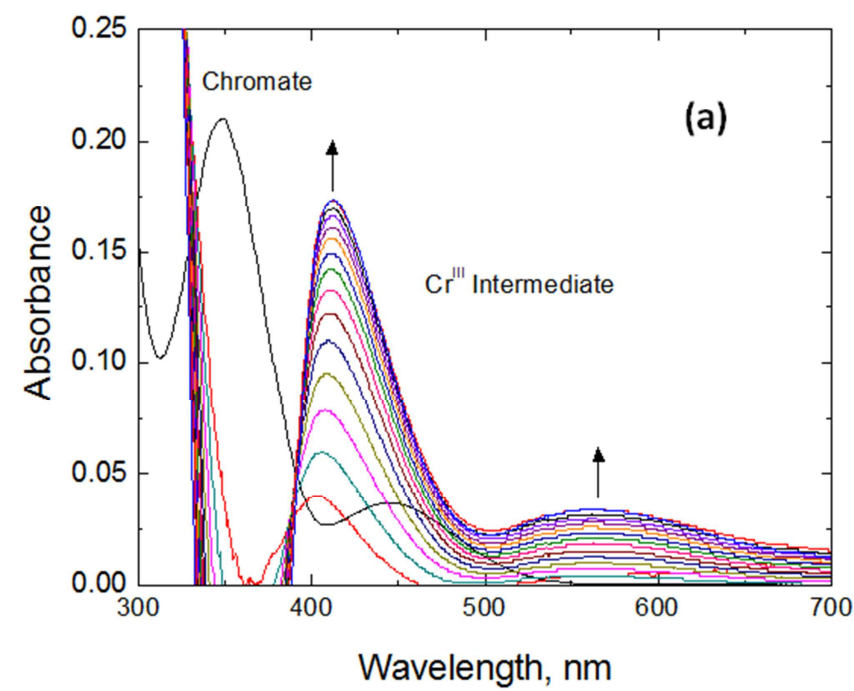

\subsection{Effect of $\left[\mathrm{H}^{+}\right]$on the Oxidation Rate}

To explore the effect of hydrogen ion concentration on the reaction rate, kinetic runs were carried out by varying the hydrogen ion concentration $\left(1.0-3.0 \mathrm{~mol} \mathrm{dm}^{-3}\right)$ at constant $[\mathrm{MAPF}],\left[\mathrm{Cr}^{\mathrm{VI}}\right]$, ionic strength and temperature. An increase in acid concentration was found to accelerate the oxidation rate (Table 1) indicating that the oxidation process is acidcatalyzed. A plot of $k_{\mathrm{obs}}$ versus $\left[\mathrm{H}^{+}\right]$was found to be linear with a positive intercept on $k_{\text {obs }}$ axis suggesting that the reaction was fractional-first order (Figure not shown).

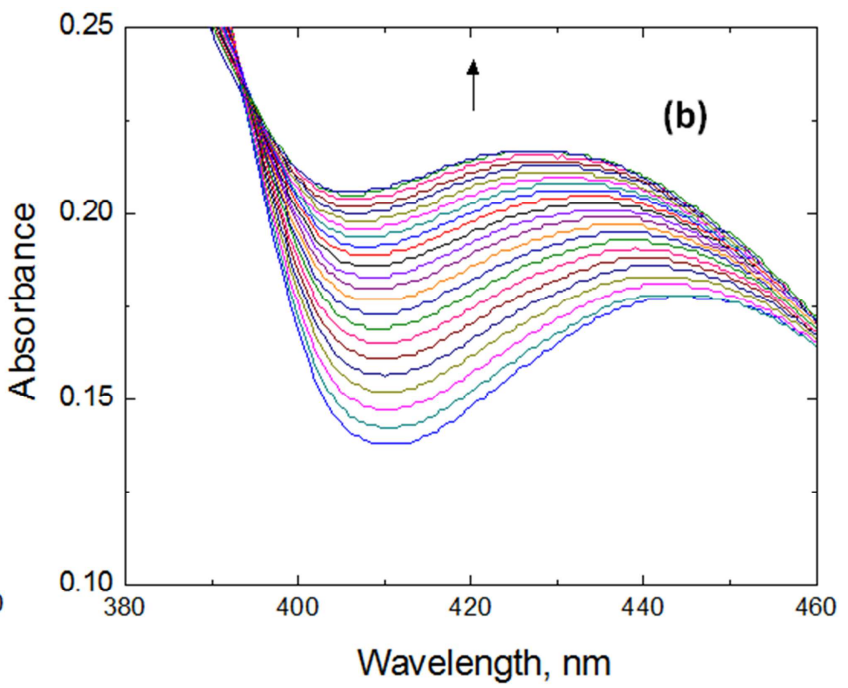

Figure 2. Careful examination of: a) Spectra focused from Figure 1, and b) New spectra where reference cell contains $\mathrm{Cr}^{V I}$ and $H^{+}$of the same reaction mixture concentration.

Table 1. Effect of variation of $\left[\mathrm{Cr}^{V I}\right],[\mathrm{MAPF}],\left[\mathrm{H}^{+}\right]$and ionic strength (I) on the observed first order rate constant $k_{\text {obs }}$ in the chromic acid oxidation of MAPF in sulfuric acid solution at $25^{\circ} \mathrm{C}$.

\begin{tabular}{|c|c|c|c|c|}
\hline $10^{4}\left[\mathrm{Cr}^{\mathrm{VI}}\right]\left(\mathrm{mol} \mathrm{dm}^{-3}\right)$ & $10^{2}[\mathrm{MAPF}]\left(\mathrm{mol} \mathrm{dm}^{-3}\right)$ & {$\left[\mathrm{H}^{+}\right]\left(\mathrm{mol} \mathrm{dm}^{-3}\right)$} & $I(\mathrm{~mol} \mathrm{dm})$ & $10^{5} k_{\text {obs }}\left(\mathrm{s}^{-1}\right)$ \\
\hline 3.0 & 1.0 & 2.0 & 3.0 & 54.3 \\
\hline 4.0 & 1.0 & 2.0 & 3.0 & 55.7 \\
\hline 5.0 & 1.0 & 2.0 & 3.0 & 56.2 \\
\hline 6.0 & 1.0 & 2.0 & 3.0 & 57.3 \\
\hline 7.0 & 1.0 & 2.0 & 3.0 & 55.9 \\
\hline 8.0 & 1.0 & 2.0 & 3.0 & 57.5 \\
\hline 5.0 & 0.4 & 2.0 & 3.0 & 27.0 \\
\hline 5.0 & 0.6 & 2.0 & 3.0 & 38.3 \\
\hline 5.0 & 0.8 & 2.0 & 3.0 & 48.1 \\
\hline 5.0 & 1.0 & 2.0 & 3.0 & 56.2 \\
\hline 5.0 & 1.2 & 2.0 & 3.0 & 64.9 \\
\hline 5.0 & 1.4 & 2.0 & 3.0 & 70.8 \\
\hline 5.0 & 1.0 & 0.5 & 3.0 & 16.9 \\
\hline 5.0 & 1.0 & 1.0 & 3.0 & 29.1 \\
\hline 5.0 & 1.0 & 2.0 & 3.0 & 56.2 \\
\hline 5.0 & 1.0 & 2.5 & 3.0 & 70.2 \\
\hline 5.0 & 1.0 & 3.0 & 3.0 & 81.7 \\
\hline 5.0 & 1.0 & 2.0 & 3.0 & 56.7 \\
\hline 5.0 & 1.0 & 2.0 & 3.3 & 55.3 \\
\hline 5.0 & 1.0 & 2.0 & 3.6 & 57.0 \\
\hline 5.0 & 1.0 & 2.0 & 3.9 & 61.4 \\
\hline 5.0 & 1.0 & 2.0 & 4.2 & 57.2 \\
\hline 5.0 & 1.0 & 2.0 & 4.5 & 55.8 \\
\hline
\end{tabular}

Experimental error $\pm 4 \%$. 


\subsection{Effect of Ionic Strength and Solvent Polarity of the Medium}

The ionic strength was varied from 3.0 to $4.5 \mathrm{~mol} \mathrm{dm}^{-3}$ using sodium sulfate at constant concentrations of MAPF and $\mathrm{Cr}^{\mathrm{VI}}$ and at constant $\mathrm{pH}$ and temperature. Increasing the ionic strength had a negligible effect on the reaction rate (Table 1).

To investigate the effect of the solvent polarity $(\varepsilon)$ of the reaction medium on the rate, the reaction was studied at different solvent compositions of acetic acid and water by varying the acetic acid content from 0 to $40 \%(\mathrm{~V} / \mathrm{V})$ in the reaction medium at constant other variables. As for ionic strength, changing solvent polarity of the medium did not affect the reaction rate.

\subsection{Effect of Manganous Ion on the Oxidation Rate}

To examine the contribution of $\mathrm{Cr}^{\mathrm{IV}}$ as an intermediate species of chromium in the oxidation reaction, various concentrations of manganous ion, $\mathrm{Mn}^{\mathrm{II}}$, were added to the reaction mixtures up to $0.01 \mathrm{~mol} \mathrm{dm}^{-3}$. The rate of reaction was found to decrease linearly with increasing the added $\mathrm{Mn}^{\mathrm{II}}$ as shown in Figure 3.

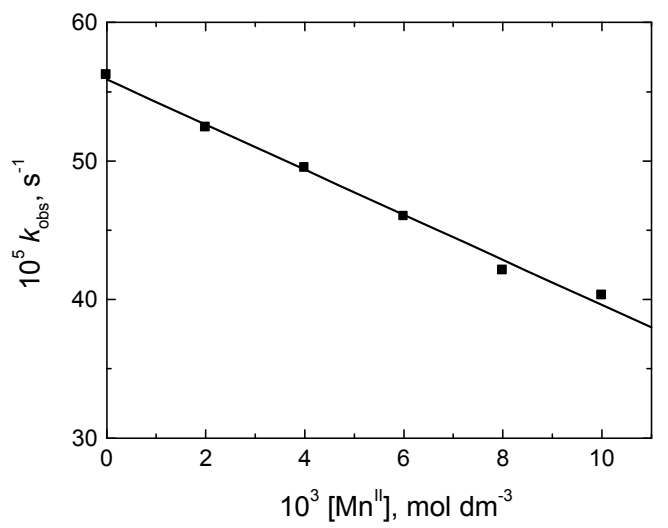

Figure 3. Effect of variation of $\left[\mathrm{Mn}^{I I}\right]$ on $k_{\text {obs }}$ in the chromic acid oxidation of $M A P F$ in sulfuric acid solution. $\left[\mathrm{Cr}^{V I}\right]=5.0 \times 10^{-4},[\mathrm{MAPF}]=0.01,\left[\mathrm{H}^{+}\right]=$ 2.0 and $\mathrm{I}=3.0 \mathrm{~mol} \mathrm{dm}^{-3}$ at $25^{\circ} \mathrm{C}$.

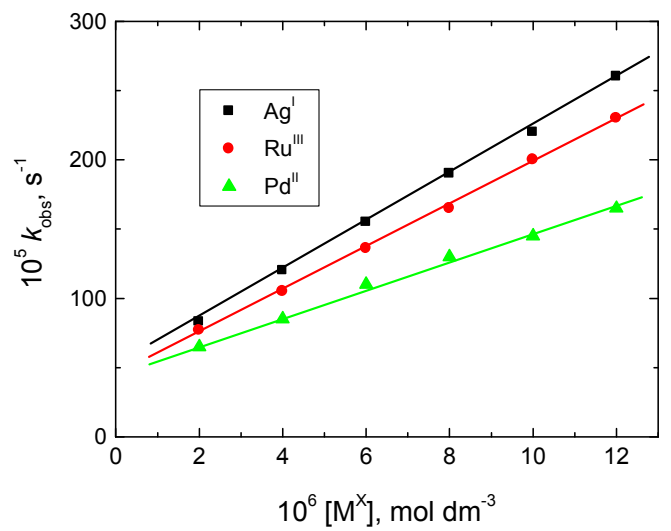

Figure 4. Effect of variation of $A g^{I}, P d^{I I}$ and $R u^{I I I}$ concentrations on the first order rate constant $k_{\text {obs }}$ in the chromic acid oxidation of MAPF in sulfuric acid solution. $\left[\mathrm{Cr}^{V I}\right]=5.0 \times 10^{-4},[\mathrm{MAPF}]=0.01,\left[\mathrm{H}^{+}\right]=2.0$ and $\mathrm{I}=3.0$ mol dm ${ }^{-3}$ at $25^{\circ} \mathrm{C}$.

\subsection{Effect of $\mathrm{Ag}^{I}, \mathrm{Pd}^{I I}$ and $\mathrm{R} \mathrm{u}^{I I I}$ Catalysts}

The reaction rate was measured at various $\mathrm{Ag}^{\mathrm{I}}, \mathrm{Pd}^{\mathrm{II}}$ and $\mathrm{Ru}^{\mathrm{III}}$ concentrations $\left(2.0-12.0 \times 10^{-6} \mathrm{~mol} \mathrm{dm}^{-3}\right)$ at constant other variables. The results show that the rate was increased with increasing metal ion concentration and the order of catalytic efficiency was: $\mathrm{Ag}^{\mathrm{I}}>\mathrm{Ru}^{\mathrm{III}}>\mathrm{Pd}^{\mathrm{II}}$ as shown in Figure 4.

\subsection{Effect of Temperature on the Oxidation Rate}

The reaction was studied at five temperatures, 15, 20, 25, 30 and $35^{\circ} \mathrm{C}$ with varying both substrate and hydrogen ion concentration keeping other conditions constant. The reaction rate was found to increase with raising temperature. The activation and thermodynamic parameters were evaluated and were listed in Tables 2 and 3, respectively.

\subsection{Polymerization Test}

The possible intervention of free radicals in the reaction was examined as follows: the reaction mixtures, to which a known quantity of acrylonitrile monomer was initially added and was kept for $6 \mathrm{~h}$ in an inert atmosphere. On diluting the reaction mixture with methanol, no white precipitate was formed thus confirming the absence of free radical in the reaction.

\section{Discussion}

Two reaction mechanisms for electron transfer were suggested [20] for redox reactions involving chromium(VI) as an oxidant in acid media. The first mechanism involves a successive one-electron transfer in two steps. The second one involves a simultaneous two-electron transfer in a single step. However, both successive one-electron and simultaneous two-electron changes may be considered during reduction of chromium(VI) leading to formation of either $\mathrm{Cr}^{\mathrm{V}}$ or $\mathrm{Cr}^{\mathrm{IV}}$ intermediate species, respectively [21-23]. In the present investigation, the negative result for free radical intervention ruled out the formation of $\mathrm{Cr}^{\mathrm{V}}$ intermediate species. On the other hand, the contribution of $\mathrm{Cr}^{\mathrm{IV}}$ as an intermediate species during the reaction can be proved by inhibition of the oxidation rates upon addition of $\mathrm{Mn}^{\mathrm{II}}$ to the reaction medium. This is because $\mathrm{Mn}^{\mathrm{II}}$ has been recognized as a frequently tool for trapping $\mathrm{Cr}^{\mathrm{IV}}$ intermediate [24]. Therefore, if $\mathrm{Cr}^{\mathrm{IV}}$ intermediate is involved, addition of $\mathrm{Mn}^{\mathrm{II}}$ to the reaction mixture will remove it from the oxidation reaction resulting in a decrease in the oxidation rate according to the equation, $\mathrm{Cr}^{\mathrm{IV}}+\mathrm{Mn}^{\mathrm{II}}=\mathrm{Cr}^{\mathrm{III}}+\mathrm{Mn}^{\mathrm{III}}$. The notable decrease in the oxidation rate upon addition of $\mathrm{Mn}^{\mathrm{II}}$ (Figure 3 ) is considered as good evidence to the contribution of $\mathrm{Cr}^{\mathrm{IV}}$. The inhibition effect occurs due to the competition existing between the substrate and $\mathrm{Mn}^{\mathrm{II}}$ to react with $\mathrm{Cr}^{\mathrm{IV}}$.

In aqueous acid media, chromium(VI) was suggested [25, 26] to exist mainly as acid chromate, $\mathrm{H}_{2} \mathrm{CrO}_{4}$, as represented by the first step in Figure 5. The enhancement of the oxidation rate upon increasing hydrogen ion concentration confirmed a protolytic process of the chromate ion, i.e. the 
protonated species of the chromate oxidant $\left(\mathrm{H}_{2} \mathrm{CrO}_{4}\right)$ may be considered as the kinetically reactive species which play the main role in the oxidation kinetics.

The present reaction between chromic acid and MAPF in $\mathrm{H}_{2} \mathrm{SO}_{4}$ solution showed a stoichiometry of $2: 3\left(\mathrm{Cr}^{\mathrm{VI}}\right.$ : MAPF $)$ with a first order dependence on $\left[\mathrm{Cr}^{\mathrm{VI}}\right]$ and a fractional-first order kinetics with respect to [MAPF]. The fractional order dependence on MAPF concentration can be attributed to complex formation between MAPF and chromic acid in a pre-equilibrium step. The formation of the complex was also proved kinetically by a non-zero intercept of the plot of $1 / k_{\mathrm{obs}}$ versus 1/[MAPF] as shown in Figure 6. Further evidence for complex formation was obtained from the UV-Vis spectra as shown in Figure 1. A similar spectrophotometric observation was reported earlier [27, 28]. The complex formation between chromium(VI) and different organic compounds in acid media was also reported [28, 29]. Furthermore, the negligible effects of ionic strength and solvent polarity of the medium were consistent with a reaction occurs between an ion and a neutral molecule or between two neutral molecules $[30,31]$ i.e. between MAPF and $\mathrm{H}_{2} \mathrm{CrO}_{4}$.

Hence, the most reasonable reaction mechanism which may be suggested (see Figure 5), involves a fast complexation between the reductant MAPF and chromic acid oxidant to give an intermediate complex (C). The latter was slowly decomposed in the rate-determining step followed by subsequent fast steps, to give rise to the final oxidation products.

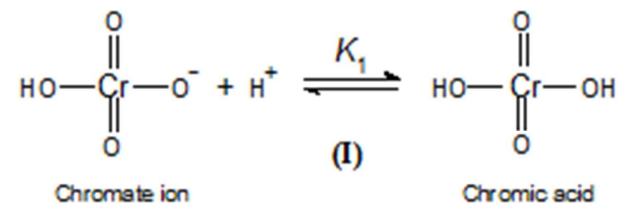<smiles>Cc1cc(N=CC(=O)O)n[nH]1</smiles><smiles>CC=CC(=O)N(C)C(=O)O</smiles>

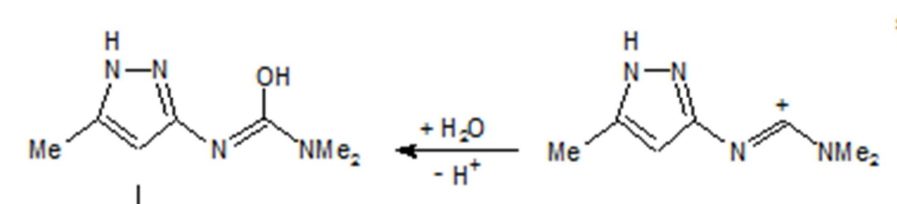

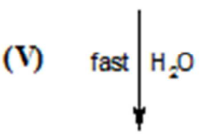<smiles>CC(C)[C@H](C)C(=O)O</smiles>

(III)

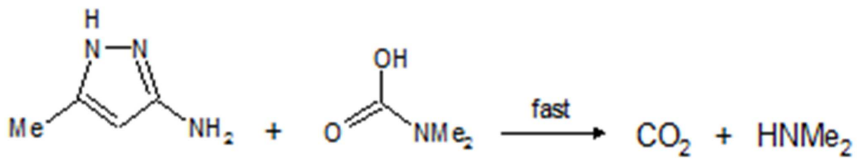

(VI)

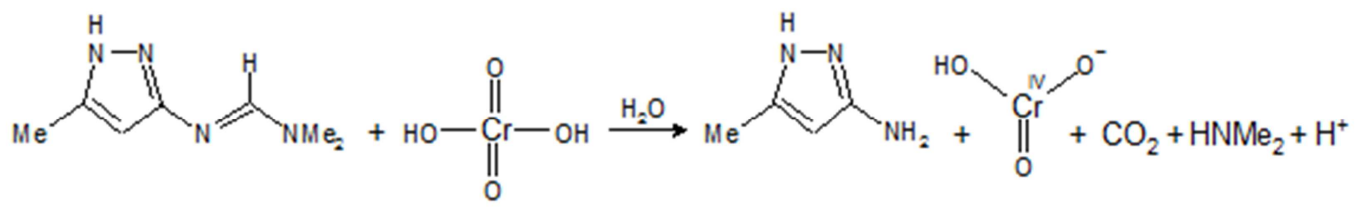

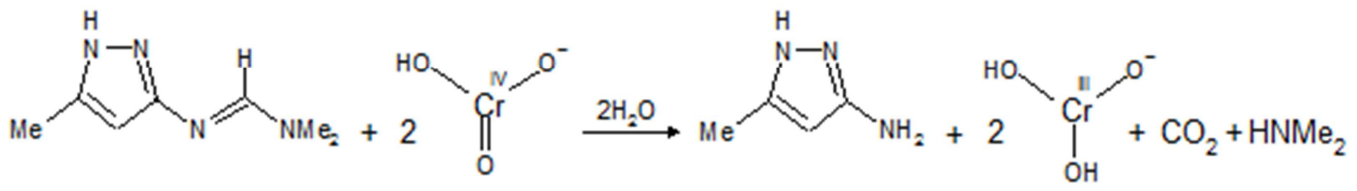

Figure 5. Mechanistic scheme of the chromic acid oxidation of MAPF in aqueous sulfuric acid solution. 
The suggested mechanistic Figure 5 leads to the following rate law (see Appendix A),

$$
\text { Rate }=\frac{k_{1} K_{1} K_{2}\left[\mathrm{HCrO}_{4}^{-}\right][\mathrm{MAPF}]\left[\mathrm{H}^{+}\right]}{1+K_{1}\left[\mathrm{H}^{+}\right]+K_{1} K_{2}[\mathrm{MAPF}]\left[\mathrm{H}^{+}\right]}
$$

Under pseudo-first order condition,

$$
\text { Rate }=\frac{-d\left[\mathrm{HCrO}_{4}^{-}\right]}{d t}=k_{\mathrm{obs}}\left[\mathrm{HCrO}_{4}^{-}\right]
$$

Comparison of Eqs. (1) and (2) gives,

$$
k_{\mathrm{obs}}=\frac{k_{1} K_{1} K_{2}[\mathrm{MAPF}]\left[\mathrm{H}^{+}\right]}{1+K_{1}\left[\mathrm{H}^{+}\right]+K_{1} K_{2}[\mathrm{MAPF}]\left[\mathrm{H}^{+}\right]}
$$

and with rearrangement of Eq. (3) leads to the following equations,

$$
\begin{gathered}
\frac{1}{k_{\mathrm{obs}}}=\left(\frac{1+K_{1}\left[\mathrm{H}^{+}\right]}{k_{1} K_{1} K_{2}\left[\mathrm{H}^{+}\right]}\right) \frac{1}{[\mathrm{MAPF}]}+\frac{1}{k_{1}} \\
\frac{1}{k_{\mathrm{obs}}}=\left(\frac{1}{k_{1} K_{1} K_{2}[\mathrm{MAPF}]}\right) \frac{1}{\left[\mathrm{H}^{+}\right]}+\left(\frac{1}{k_{1} K_{2}[\mathrm{MAPF}]}+\frac{1}{k_{1}}\right)
\end{gathered}
$$

Owing to Eqs. (4) and (5), plots of $1 / k_{\mathrm{obs}}$ versus $1 /[\mathrm{MAPF}]$ at constant $\left[\mathrm{H}^{+}\right]$and plots of $1 / k_{\text {obs }}$ versus $1 /\left[\mathrm{H}^{+}\right]$at constant [MAPF] should give straight lines with positive intercepts on the $1 / k_{\text {obs }}$ axes, as were experimentally observed (Figures 6 and 7 , respectively). Values of the rate constant of the slow step $\left(k_{1}\right)$ along with the equilibrium constants $K_{1}$ and $K_{2}$ at different temperatures were calculated from the slopes and intercepts of such plots and were listed in Tables 2 and 3, respectively. The obtained values of the protonation constant of mono hydrogen chromate $\left(K_{1}\right)$ are in agreement with those reported in the literature [32].

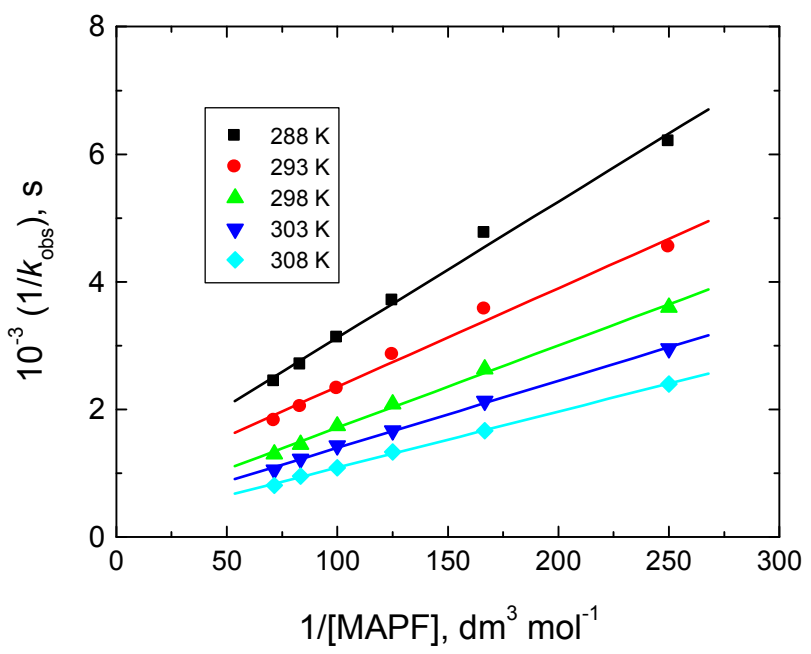

Figure 6. Plots of $1 / k_{\text {obs }}$ versus $1 /[M A P F]$ in the oxidation of MAPF by chromic acid in sulfuric acid solution at different temperatures. $\left[\mathrm{Cr}^{\mathrm{HI}}\right]=5.0$ $x 10^{-4},\left[\mathrm{H}^{+}\right]=2.0$ and $I=3.0 \mathrm{~mol} \mathrm{dm}^{-3}$.

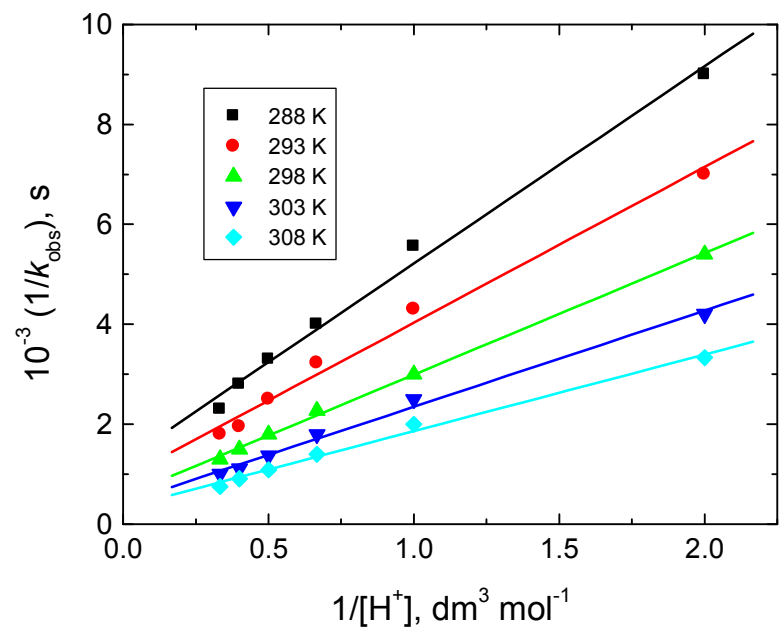

Figure 7. Plots of $1 / k_{\text {obs }}$ versus $1 /\left[H^{+}\right]$in the oxidation of MAPF by chromic acid in sulfuric acid solutions at different temperatures. $\left[\mathrm{Cr}^{V I}\right]=5.0 \times 10^{-4}$, $[M A P F]=0.01$ and $I=3.0 \mathrm{~mol} \mathrm{dm}^{-3}$.
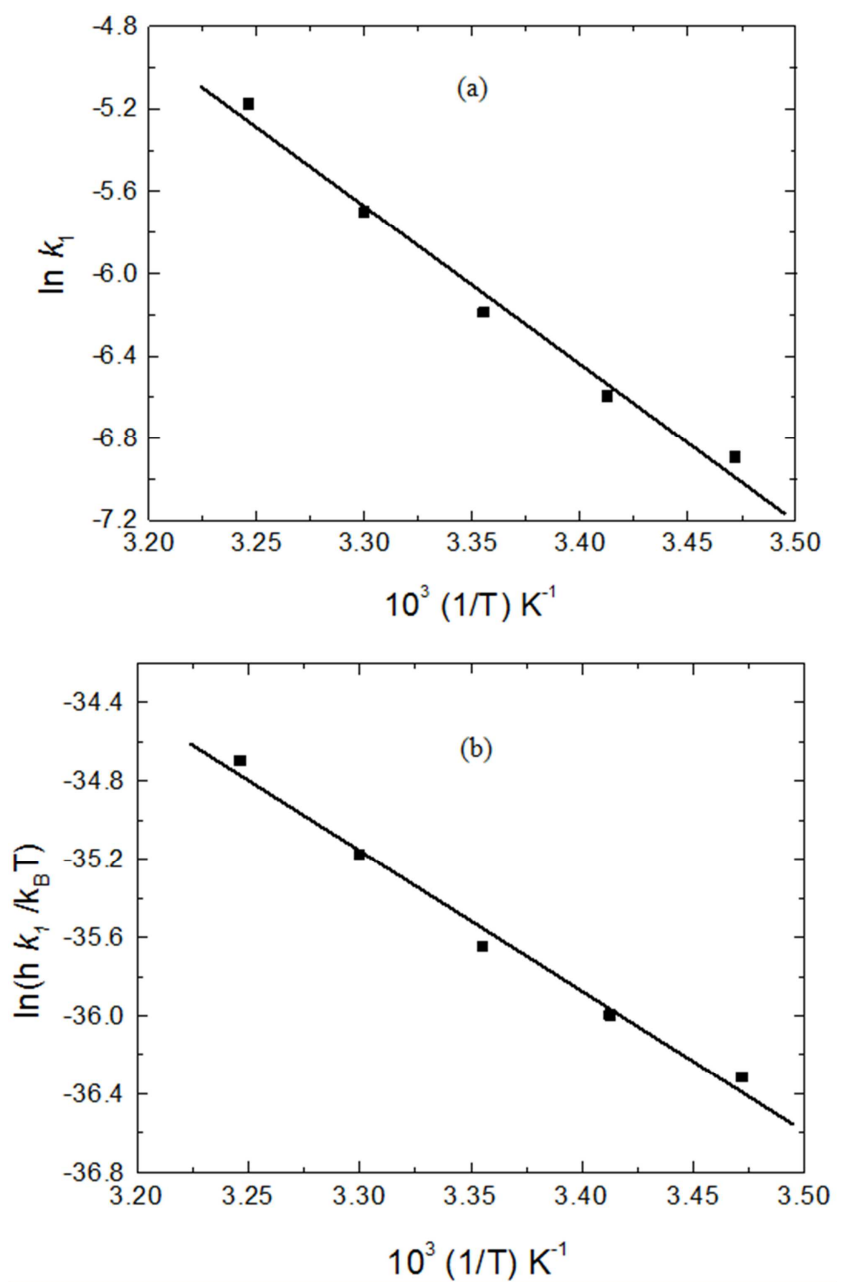

Figure 8. a) Arrhenius plot, and b) Eyring plot of $k_{1}$ in the oxidation of MAPF by chromic acid in sulfuric acid solution. $\left[\mathrm{Cr}^{V I}\right]=5.0 \times 10^{-4},[\mathrm{MAPF}]$ $=0.01,\left[H^{+}\right]=2.0$ and $I=3.0 \mathrm{~mol} \mathrm{dm}^{-3}$.

The activation parameters of the rate constants of the slow step $\left(k_{1}\right)$ are calculated using Arrhenius (Figure 8a) 
and Eyring (Figure 8b) plots, and were listed in Table 2. Furthermore, the thermodynamic parameters of the equilibrium constants were also determined using a van't Hoff plots (Figure 9) and were also listed in Table 3.

The obtained large negative values of $\Delta S^{\neq}$are consistent with the formation of compacted intermediate complex and such activated complex is more ordered than the reactants due to loss of degree of freedom. The experimental values of $\Delta H^{\ddagger}$ and $\Delta S^{\ddagger}$ were both favorable for electron-transfer process [33]. Again, the positive values of $\Delta H^{\ddagger}$ and $\Delta G^{\ddagger}$ indicate endothermic formation of the intermediate and its non-spontaneity, respectively.

On the other hand, the enhancement of oxidation rate upon addition of the metal cations $\mathrm{Ag}^{\mathrm{I}}, \mathrm{Pd}^{\mathrm{II}}$ and $\mathrm{Ru}^{\mathrm{III}}$ may be interpreted by formation of complexes with the reactants and, hence, facilitate the electron transfer, or oxidation of the substrate itself [34-36].

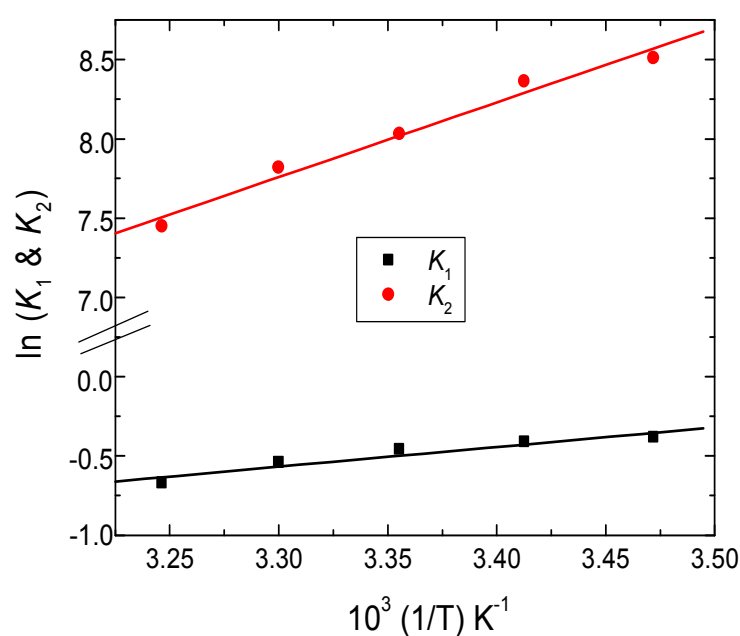

Figure 9. Van't Hoff plots of $K_{1}$ and $K_{2}$ in the oxidation of MAPF by chromic acid in sulfuric acid solution. $\left[\mathrm{Cr}^{V I}\right]=5.0 \times 10^{-4},[\mathrm{MAPF}]=0.01,\left[\mathrm{H}^{+}\right]=2.0$ and $I=3.0 \mathrm{~mol} \mathrm{dm}^{-3}$.

Table 2. Values of the rate constant of the slow step $\left(k_{l}\right)$ at different temperatures and its associated activation parameters in the oxidation of MAPF by chromic acid in sulfuric acid solution.

\begin{tabular}{|c|c|c|c|c|c|c|c|c|c|}
\hline \multirow{2}{*}{ Rate Constant $\left(\mathrm{s}^{-1}\right)$} & \multicolumn{5}{|c|}{ Temperature (K) } & \multicolumn{4}{|c|}{ Activation parameters } \\
\hline & 288 & 293 & 298 & 303 & 308 & $\Delta S^{\ddagger}\left(\mathrm{Jmol}^{-1} \mathbf{K}^{-1}\right)$ & $\Delta H^{\ddagger}\left(\mathrm{kJ} \mathrm{mol}^{-1}\right)$ & $\Delta G_{298}^{\ddagger}\left(\mathrm{kJ} \mathrm{mol}^{-1}\right)$ & $E_{\mathrm{a}}^{\neq}\left(\mathrm{kJ} \mathrm{mol}^{-1}\right)$ \\
\hline $10^{3} k_{1}$ & 1.01 & 1.29 & 2.04 & 3.33 & 5.88 & -94.78 & 59.78 & 88.02 & 63.68 \\
\hline
\end{tabular}

Experimental error $= \pm 4 \%$.

Table 3. Values of the equilibrium constants $\left(K_{1}\right.$ and $\left.K_{2}\right)$ at different temperatures and their thermodynamic quantities in the oxidation of MAPF by chromic acid in sulfuric acid solution.

\begin{tabular}{|c|c|c|c|c|c|c|c|c|}
\hline \multirow{2}{*}{ Equilibrium Constant $\left(\mathrm{dm}^{3} \mathrm{~mol}^{-1}\right)$} & \multicolumn{5}{|c|}{ Temperature (K) } & \multicolumn{3}{|c|}{ Thermodynamic parameters } \\
\hline & 288 & 293 & 298 & 303 & 308 & $\Delta H^{o}\left(\mathrm{~kJ} \mathrm{~mol}^{-1}\right)$ & $\Delta G_{298}^{o}\left(\mathrm{~kJ} \mathrm{~mol}^{-1}\right)$ & $\Delta S^{o}\left(\mathrm{Jmol}^{-1} \mathrm{~K}^{-1}\right)$ \\
\hline$K_{1}$ & 0.68 & 0.66 & 0.63 & 0.58 & 0.51 & -10.31 & 1.14 & -38.42 \\
\hline $10^{-2} K_{2}$ & 4.94 & 4.27 & 3.06 & 2.48 & 1.71 & -39.22 & -19.88 & -64.90 \\
\hline
\end{tabular}

Experimental error $\pm 5 \%$.

\section{Conclusions}

The oxidation of methylaminopyrazole formamidine (MAPF) by chromic acid was studied in sulfuric acid solutions. $\mathrm{H}_{2} \mathrm{CrO}_{4}$ is suggested to be the kinetically active species of the oxidant which takes part in the oxidation reaction. The final oxidation products of MAPF were identified as methylaminopyrazole, dimethylamine and carbon dioxide.

A spectral evidence for the formation of chromium(III) product was obtained. A mechanism which proposed for the oxidation reaction is in conformity with the kinetic findings. The rate and equilibrium constants involved in the different steps of the proposed mechanism along with their activation and thermodynamic parameters are evaluated and discussed.

\section{Appendix A}

According to the suggested reaction mechanism, and regarding to steps (I) and (II) in Scheme 1,

$$
K_{1}=\frac{\left[\mathrm{H}_{2} \mathrm{CrO}_{4}\right]}{\left[\mathrm{HCrO}_{4}^{-}\right]\left[\mathrm{H}^{+}\right]},\left[\mathrm{H}_{2} \mathrm{CrO}_{4}\right]=K_{1}\left[\mathrm{HCrO}_{4}^{-}\right]\left[\mathrm{H}^{+}\right]
$$

and $K_{2}=\frac{[\mathrm{C}]}{[\mathrm{MAPF}]\left[\mathrm{H}_{2} \mathrm{CrO}_{4}\right]}$,

$$
[\mathrm{C}]=K_{2}[\mathrm{MAPF}]\left[\mathrm{H}_{2} \mathrm{CrO}_{4}\right]=K_{1} K_{2}[\mathrm{MAPF}]\left[\mathrm{HCrO}_{4}^{-}\right]\left[\mathrm{H}^{+}\right](\mathrm{A} .2)
$$

From step (III) in Scheme 1, the rate law expression can be expressed by Eq. (A.3),

$$
\text { Rate }=\frac{-d\left[\mathrm{HCrO}_{4}^{-}\right]}{d t}=k_{1}[\mathrm{C}]
$$

Substituting Eq. (A.2) into Eq. (A.3) leads to,

$$
\text { Rate }=k_{1} K_{1} K_{2}[\mathrm{MAPF}]\left[\mathrm{HCrO}_{4}^{-}\right]\left[\mathrm{H}^{+}\right]
$$

The total concentration of $\mathrm{HCrO}_{4}{ }^{-}$is given by,

$$
\left[\mathrm{HCrO}_{4}^{-}\right]_{\mathrm{T}}=\left[\mathrm{HCrO}_{4}^{-}\right]_{\mathrm{F}}+\left[\mathrm{H}_{2} \mathrm{CrO}_{4}\right]+[\mathrm{C}]
$$


where ' $\mathrm{T}$ ' and ' $\mathrm{F}$ ' stand for total and free.

Substituting Eq. (A.1) into Eq. (A.5) gives,

$$
\begin{gathered}
{\left[\mathrm{HCrO}_{4}^{-}\right]_{\mathrm{T}}=\left[\mathrm{HCrO}_{4}^{-}\right]_{\mathrm{F}}+K_{1}\left[\mathrm{HCrO}_{4}^{-}\right]\left[\mathrm{H}^{+}\right]+} \\
K_{1} K_{2}[\mathrm{MAPF}]\left[\mathrm{HCrO}_{4}^{-}\right]\left[\mathrm{H}^{+}\right]
\end{gathered}
$$

$\left[\mathrm{HCrO}_{4}^{-}\right]_{\mathrm{T}}=\left[\mathrm{HCrO}_{4}^{-}\right]_{\mathrm{F}}\left(1+K_{1}\left[\mathrm{H}^{+}\right]+K_{1} K_{2}[\mathrm{MAPF}]\left[\mathrm{H}^{+}\right]\right)(\mathrm{A} .7)$

Therefore,

$$
\left[\mathrm{HCrO}_{4}^{-}\right]_{\mathrm{F}}=\frac{\left[\mathrm{HCrO}_{4}^{-}\right]_{\mathrm{T}}}{1+K_{1}\left[\mathrm{H}^{+}\right]+K_{1} K_{2}[\mathrm{MAPF}]\left[\mathrm{H}^{+}\right]}
$$

Also, the total concentration of MAPF is given by,

$$
[\mathrm{MAPF}]_{\mathrm{T}}=[\mathrm{MAPF}]_{\mathrm{F}}+[\mathrm{C}]
$$

Substituting Eq. (A.2) into Eq. (A.9) leads to,

$$
\begin{aligned}
{[\mathrm{MAPF}]_{\mathrm{T}} } & =[\mathrm{MAPF}]_{\mathrm{F}}+K_{1} K_{2}[\mathrm{MAPF}]\left[\mathrm{HCrO}_{4}{ }^{-}\right]\left[\mathrm{H}^{+}\right] \\
{[\mathrm{MAPF}]_{\mathrm{T}} } & =[\mathrm{MAPF}]_{\mathrm{F}}\left(1+K_{1} K_{2}\left[\mathrm{HCrO}_{4}^{-}\right]\left[\mathrm{H}^{+}\right]\right)
\end{aligned}
$$

Therefore,

$$
[\mathrm{MAPF}]_{\mathrm{F}}=\frac{[\mathrm{MAPF}]_{\mathrm{T}}}{1+K_{1} K_{2}\left[\mathrm{HCrO}_{4}^{-}\right]\left[\mathrm{H}^{+}\right]}
$$

Because of low concentration of $\mathrm{HCrO}_{4}^{-}$used, the term $K_{1} K_{2}\left[\mathrm{HCrO}_{4}^{-}\right]\left[\mathrm{H}^{+}\right]$in the denominator can be neglected. Hence,

$$
[\mathrm{MAPF}]_{\mathrm{F}}=[\mathrm{MAPF}]_{\mathrm{T}}
$$

In view of the high concentrations of $\left[\mathrm{H}^{+}\right]$we can write,

$$
\left[\mathrm{H}^{+}\right]_{\mathrm{F}}=\left[\mathrm{H}^{+}\right]_{\mathrm{T}}
$$

Substituting Eqs. (A.8), (A.13) and (A.14) into Eq. (A.4) (and omitting ' $\mathrm{T}$ ' and ' $\mathrm{F}$ ' subscripts) gives,

$$
\text { Rate }=\frac{k_{1} K_{1} K_{2}\left[\mathrm{HCrO}_{4}^{-}\right][\mathrm{MAPF}]\left[\mathrm{H}^{+}\right]}{1+K_{1}\left[\mathrm{H}^{+}\right]+K_{1} K_{2}[\mathrm{MAPF}]\left[\mathrm{H}^{+}\right]}
$$

Under pseudo-first order condition,

$$
\text { Rate }=\frac{-d\left[\mathrm{HCrO}_{4}^{-}\right]}{d t}=k_{\mathrm{obs}}\left[\mathrm{HCrO}_{4}^{-}\right]
$$

Comparing Eqs. (A.15) and (A.16), the following relationship is obtained,

$$
k_{\mathrm{obs}}=\frac{k_{1} K_{1} K_{2}[\mathrm{MAPF}]\left[\mathrm{H}^{+}\right]}{1+K_{1}\left[\mathrm{H}^{+}\right]+K_{1} K_{2}[\mathrm{MAPF}]\left[\mathrm{H}^{+}\right]}
$$

and with rearrangement, the following equations are obtained,

$$
\frac{1}{k_{\mathrm{obs}}}=\left(\frac{1+K_{1}\left[\mathrm{H}^{+}\right]}{k_{1} K_{1} K_{2}\left[\mathrm{H}^{+}\right]}\right) \frac{1}{[\mathrm{MAPF}]}+\frac{1}{k_{1}}
$$

$$
\frac{1}{k_{\mathrm{obs}}}=\left(\frac{1}{k_{1} K_{1} K_{2}[\mathrm{MAPF}]}\right) \frac{1}{\left[\mathrm{H}^{+}\right]}+\frac{1}{k_{1} K_{2}[\mathrm{MAPF}]}+\frac{1}{k_{1}}
$$

\section{References}

[1] Beeman RW, Matsumura F (1973) Chlordimeform: a pesticide acting upon amine regulatory mechanisms. Nature. 242: 273274.

[2] Aziz AA, Knowles CO (1973) Inhibition of monoamine oxidase by the pesticides chlordimeform and related compounds. Nature 242: 417-418.

[3] Leung VSK, Chan TYK, Yeung VTF (1999) Ami-traz poisoning in humans, Clinical Toxicol. 37: 513-514.

[4] Nakayama A, Sukekawa M, Eguchi Y (1997) Stereochemistry and active conformation of a novel insecticide Acetamiprid. Pesticide Sci. 51: 157-164.

[5] Katz SA, Salem H (1993) The toxicology of chromium with respect to its chemical speciation: a review. J. Appl. Toxicol. 13: $217-224$

[6] Barnhart J (1997) Chromium in soil: perspectives in chemistry, health, and environmental regulation. J. Soil Contamination 61 561-568.

[7] Costa $\mathrm{M}$ (1997) Toxicity and carcinogenicity of $\mathrm{Cr}^{\mathrm{VI}}$ in animal models and humans. CRC, Crit. Rev. Toxicol. 27: 431-442.

[8] Chimatadar SA, Koujalagi SB, Nandibewoor ST (2001) Kinetics and mechanism of palladium(II) catalyzed chromium(VI) oxidation of mercury(I) in aqueous sulphuric acid. Transition Met. Chem. 26: 662-667; Chimatadar SA, Basavaraj T, Nandibewoor ST (2006) Mechanistic study of quinoliniumdichromate (QDC) oxidation of mercury(I) in aqueous sulfuric acid in the presence of micro amounts of palladium(II). Autocatalysis in catalysis. Polyhedron 25: 2976-2984.

[9] Sen Gupta KK, Chakladar JK (1974) Kinetics of the chromic acid oxidation of arsenic(II). J. Chem. Soc. Dalton Trans. 2: 222-225.

[10] Sen Gupta KK, Chakladar JK, Chatterjee AK, Chakladar JK (1973) Kinetics of the oxidation of hypophosphorous and phosphorous acids by chromium(VI). J. Inorg. Nucl. Chem. 35: 901-908.

[11] Espenson JH (1970) Oxidation of transition metal complexes by chromium(VI). Accounts Chem. Res. 3: 347-351.

[12] Hasan F, Rocek J (1975) Three-electron oxidations. IX Chromic acid oxidation of glycolic acid. J. Am. Chem. Soc. 97: 1444-1450.

[13] Khan Z, Id-Din K (2001) Effect of manganese(II) ions on the oxidation of maleic and oxaloethanoic acids by aqueous $\mathrm{H}_{2} \mathrm{CrO}_{4}$. Transition Met. Chem. 26: 672-678.

[14] Manhas MS, Kumar P, Mohamed F, Khan Z (2008) Oxidative degradation of non-ionic surfactant (Triton X-100) by chromium(VI). Coll. Surf. A 320: 240-246.

[15] Odebunmi EO, Obike AI, Owalude SO (2009) Kinetics and mechanism of oxidation of D-xylose and L-arabinose by chromium(VI) ions in perchloric acid medium, Int. J. Biolog. Chem. Sci. 3: 178-185. 
[16] Fawzy A, Shaaban MR (2014) Kinetic and mechanistic investigations on the oxidation of N'-heteroaryl unsymmetrical formamidines by permanganate in aqueous alkaline medium, Transition Met. Chem. 39: 379-386.

[17] Vogel AI (1973) Text Book of Practical Organic Chemistry including Quantitative Organic Analysis. 3rd edn, pp. 332, ELBS, Longman.

[18] Feigl F (1957) Spot Tests in Organic Analysis, Elsevier, New York, NY, USA.

[19] Bayen R, Das AK (2009) Kinetics and mechanism of oxidation of D-galactose by chromium(VI) in presence of $2,2^{\prime}$-bipyridine catalyst in aqueous micellar media. The Open Catal. J. 2: 71-78.

[20] Espenson JH, King EL (1963) Kinetics and mechanism of reaction of chromium(VI) and iron(II) species in acidic medium, J. Am. Chem. Soc. 85: 3328-3333.

[21] Espenson EH, Wang RT (1972) The oxidation of uranium(IV) by chromium(VI) and the induced oxidation of iodide ions. Inorg. Chem. 11: 955-959.

[22] Sen Gupta KK, Sarkar T (1975) Kinetics of the chromic acid oxidation of glyoxylic and pyruvic acids. Tetrahedron 31: $123-129$.

[23] Bose RN, Moghaddas B, Gelerinter E (1992) Long-lived chromium(IV) and chromium(V) metabolites in the chromium(VI)-glutathione reaction: NMR, ESR, HPLC, and kinetic characterization, Inorg. Chem. 31: 1987-1994.

[24] Milazzo, G, Caroli S, Sharma VK (1978) Tables of Standard Electrode Metal Potentials, Wiley \& Sons, New York.

[25] Bailey N, Carrington A, Lott KAK, Symons MCR (1960) Structure and reactivity of the oxyanions of transition metals. Part VIII. Acidities and spectra of protonated oxyanions, J. Chem. Soc. 290-297.

[26] Sasaki Y (1962) Equilibrium studies on polyanions. 9. The first steps of acidification of chromate Ion in $3 \mathrm{M} \mathrm{Na}\left(\mathrm{ClO}_{4}\right)$ Medium at 25 degrees C. Acta Chem. Scand. 16: 719-734.
[27] Naik PK, Chimatadar SA, Nandibewoor ST (2008) A kinetic and mechanistic study of the oxidation of tyrosine by chromium(VI) in aqueous perchloric acid medium Transition Met. Chem. 33: 405-410.

[28] Day MC, Selbin JJ (1964) Theoretical inorganic chemistry, Reinhold Publishing Corporation, New York.

[29] Fawzy A, Ashour SS, Musleh MA, Hassan RM, Asghar BH (2014) Kinetics and mechanistic approach to the chromic acid oxidation of L-tryptophan with a spectral detection of chromium(III) product. J. Saudi Chem. Soc. in press.

[30] Frost AA, Person RG (1971) Kinetics and Mechanism, Wiley Eastern, New Delhi, 1970; C. H. Rochester, Progress in Reaction Kinetics, Pergamon Press, Oxford; Laidler K (1965) Chemical Kinetics, McGraw-Hill, New York.

[31] Amis ES (1966) Solvent Effects on Reaction Rates and Mechanism, Academic Press, New York.

[32] Freeman WH (2010)Dissociation Constants. Inorganic Chemistry, pp. 22-25, 1983; W. H. Freeman, and Company, New York; IUPAC SC-Database (2001) A comprehensive database of published data on equilibrium constants of metal complexes and ligands. Inorganic Chemistry, Higher Education Press, Beijing, China.

[33] Rangappa KS, Raghavendra MP, Mahadevappa DS, Channagouda D (1988) Sodium N-chlorobenzenesulfonamide as a selective oxidant for hexosamines in alkaline medium: A kinetic and mechanistic study. J. Org. Chem. 63: 531-536.

[34] Fawzy A (2014) Influence of copper(II) catalyst on the oxidation of L-histidine by platinum(IV) in alkaline medium: a kinetic and mechanistic study. Transition Met. Chem. 39: 567-576.

[35] Fawzy A, Asghar BH (2015) Kinetics and mechanism of uncatalyzed and silver(I)-catalyzed oxidation of L-histidine by hexachloroplatinate(IV) in acid medium. Transition Met. Chem. 40: 287-295.

[36] Shukla A, Gupta S, Upadhyay SK (1991) Pd(II) complexes of amino alcohols and their reaction with chloramine-T: A kinetic study, Int. J. Chem. Kinet. 23: 279-288. 